\title{
Tolerance Types and Features of Intercultural Adaptation in International Students
}

\author{
Irina A. Novikova, PhD \\ Alexey L. Novikov, PhD \\ Peoples' Friendship University of Russia \\ 6 Miklukho-Maklay St., Moscow, Russia, 117198
}

Doi:10.5901/jesr.2013.v3n7p625

\section{Abstract}

The paper presents the results of a study of the types of tolerance in correlation with the features of intercultural adaptation of the international students from different parts of the world. A total of 329 respondents took part in the research, including 175 young men and 154 women from five parts of the world: Latin America, Asia, the Arab Countries, Africa, and the Central Asian region. All the respondents were the first, second and third year students of the various departments of a multinational university. The level of tolerance was measured with the help of the express-questionnaire "The Index of Tolerance" by G.U.Soldatova, O.A.Kravtsova, O.Ye.Khukhlaev, L.A.Shajgerova. The Questionnaire of the adaptation of a person to the new socio-cultural environment (APSCE) by L.V.Yankovsky, in T.G.Stefanenko and M.S.Panov's modified version, was used to define the features of intercultural adaptation of the international students. Using the factor and cluster analysis, we identified four types of tolerance among the international students: "Real tolerant", "Tolerant in ethnic relations", "Tolerant in social communications", "Intolerant" students. The types of tolerance are related to the features of intercultural adaptation of the international students. The most significant difference is between the intercultural adaptation indicators of the "real tolerant" students and the students tolerant in social communication.

Keywords: tolerance, types of tolerance, intercultural adaptation, international students, multinational university.

\section{Introduction}

In Russian psychology the problems of intercultural adaptation have been actively studied only since the late twentieth century. Russian psychologists have studied the external (social) and internal (psychological) factors of adaptation of migrants and visitors (Stefanenko, 2009). In this case, Russian colleagues are using the great experience the Western psychologists have (H. Tajel, O. Klineberg, H. Triandis, D. Berry, K. Ward, S. Bochner etc).

In the twenty-first century the academic mobility of students is growing all over the world including Russia. So the study of various factors of intercultural adaptation of international students is relevant. The study of this problem has a special importance for a multinational university such as the Peoples' Friendship University of Russia (PFUR). The PFUR, established in 1961, is a unique multinational university in which the representatives of about 140 countries of the world are trained. The mission of the PFUR is to unite people of different nationalities, races, and religious beliefs with the help of knowledge, and also to educate youth capable of working successfully in any country of the world. The team at the PFUR center for personality studies has conducted a number of basic and applied studies on ethnic characteristics and personality traits, cross-cultural communication and adaptation (Kovalenko etc, 2009). The scientists of the PFUR have also carried out a series of studies on problems of intercultural adaptation of students from Asia, Africa, South America, the Near and Middle East, and the former Soviet countries (Central Asia countries). In this research they have emphasized the role of such characteristics as the region, where the student comes from, the gender, the year of learning, emotional and social intelligence, ethnic identity, values, cultural distance, tolerance, hardiness, coping strategies, etc (Chebotareva, 2011; Maslova, 2011; Novikova, 2010 etc).

One of the most important factors of the intercultural communication and adaptation is tolerance.

In the modern Western psychology tolerance is considered from different points of view (Ibadova, 2011):

- as the value of personality, which creates the basis for peaceful coexistence in society, groups and individuals who have different views and lifestyles;

- as the attitude, which is the acceptance of the rights of other peoples to behave and think in a different from their own way. This attitude is based on sympathy and similarities, and increases the level of acceptance of originality; 
- as a personality trait (personality disposition), which is associated with the Big Five personality traits (Openness to Experience and Agreeableness).

In recent years the problem of tolerance has been thoroughly studied by the Russian scientists (not only the psychologists but the educators, linguists, sociologists, political scientists and others). Tolerance is considered in a wide range - from neuro and psychic stability to the moral imperative of personality: "Tolerance is an integral characteristic of the individual, which determines its ability in problem situations to interact with the environment with the purpose to restore its neuro-psychic balance, successful adaptation, conflict prevention and development of positive relationships with themselves and with the outside world" (Soldatova, Shaigerova, 2008, p. 9). Russian psychologists are studying different kinds of tolerance, for example, ethnic, social, communicative, and others (Soldatova, Shaigerova, 2008).

In our study, we examined tolerance as a personality trait (personality disposition).

Personality traits are significant predictors of social behavior that determine the 5 to $50 \%$ of the dispersion (Furnham, Heaven, 1999).

For example, the studies using the Five-Factor Model of Personality show that Extraversion and Openness to new experience are the predictors of a better adaptation to the new ethnic and cultural environment (Hannigan, 1990; Lievens, Harris, Van Keer, Bisqueret, 2003; Mendenhall and Oddou, 1986 etc).

Since 2007 we have been studying tolerance in the Russian and international students of the multinational University (PFUR).

For example, we compared the tolerance level of the international students from different regions of the world and revealed correlations between the parameters of tolerance and intercultural adaptation (Novikova, 2011). Firstly, it was found that, in general, the international students from all the studied regions showed medium levels of tolerance. Although Arab students showed relatively lower levels of ethnic and social tolerance, African students showed similar attitudes (especially toward interethnic relations), while the students from South America and China showed relatively higher levels of tolerance. Students from the Central Asian Region showed the highest levels of ethnic and social tolerance. Secondly, drawing from the results of the correlation and factor analysis it was concluded that the tolerance level is associated positively with the efficiency of the intercultural adaptation (especially for students from Africa, the Arab countries and South America), but it is necessary to pay attention to certain specificity of the relations of the studied parameters in the subgroup of the Chinese students, and also to consider that it is necessary to reveal factors, more closely, than the tolerance, is connected with parameters of adaptation in a subgroup of students from Central Asia (Novikova, 2011).

Also, we found out that there are four main groups of the Russian students of the PFUR with different types of tolerance:

- "intolerant" students have the lowest level of all the components of tolerance;

- "moderately tolerant" students have an average level of all the components of tolerance;

- "selectively tolerant" students have the dominance of the general and communicative tolerance over the ethnic and social tolerance;

- "real tolerant" students have the highest level of all the components of tolerance (Kovalenko et al, 2009).

In this paper we present a study of the tolerance types in the international students in correlation with the features of their intercultural adaptation.

The purpose of the study was:

1. to determine the types of tolerance in the international students from different parts of the world;

2. to reveal the relationship type of tolerance and the features of the intercultural adaptation of the international students from different parts of the world.

\section{Method}

In our research the level of tolerance was measured with the questionnaire "The Index of Tolerance" by G.U.Soldatova, O.A.Kravtsova, O.Ye.Khukhlaev, L.A.Shajgerova (Soldatova, Shaigerova, 2008). This technique consists of three scales: ethnical tolerance, social tolerance, personality tolerance:

- the Ethnic tolerance scale reflects a person's attitude towards the representatives of the other ethnic groups;

- the Social tolerance scale reflects a person's attitude to various minorities, criminals, refugees, etc.;

- the Personality Tolerance scale reflects a person's tolerant or intolerant attitude to the world as a whole (for example, tolerance to the dispute, tolerance for another point of view, the calm attitude toward disorder).

The Questionnaire of adaptation of the person to the new socio-cultural environment (APSCE) by L.V.Yankovsky, 
in T.G.Stefanenko, M.S.Panov's modified version was used to define the features of intercultural adaptation of the international students. This Questionnaire includes six scales:

- the Contentment scale reflects the degree of personal satisfaction, feelings of social and physical security, a sense of belonging to a new society and the level of activity in the new environment;

- the Interactivity scale reflects the degree of disposition to the expansion of social relations in the new society, focusing on the cooperation with the others and following the social norms;

- the Conformity scale reflects the degree of the orientation on social approval, depending on the group, the need for affection and emotional relationships with people;

- the Depression scale reflects the level of helplessness in the face of life difficulties, feelings of hopelessness, doubt, anxiety, depression, emptiness, isolation;

- the Nostalgia scale reflects the degree of internal disorder caused by the separateness of traditional values and norms, and a sense of dreamy, anguish, melancholy;

- the Alienation scale reflects the level of rejection of the new society, claims of inconsistency and real opportunities, feelings of loneliness, impatience, helplessness.

The first three scales (contentment, interactivity, conformity) correspond to rather "positive" intercultural adaptation indicators, and the last three scales (depression, nostalgia, alienation) indicate certain adaptation problems. But our research showed that nostalgia is highly manifested in most international students and its level is positively related to the positive adaptation parameters (Chebotareva, 2011; Maslova, 2011; Novikova, 2010 etc).

The factor analysis, cluster analysis, univariate analysis of variance (ANOVA), and Kruskal-Wallis test were used for processing the data.

A total of 329 respondents took part in the research, including 175 young men and 154 women (fig. 1) from the five parts of the world: Latin America, Asia (China), the Arab Countries (the countries of the Near and Middle East), Africa, and the countries of the Central Asian region (former Soviet republics). All the respondents were the first, second and third year students of various departments of the PFUR.

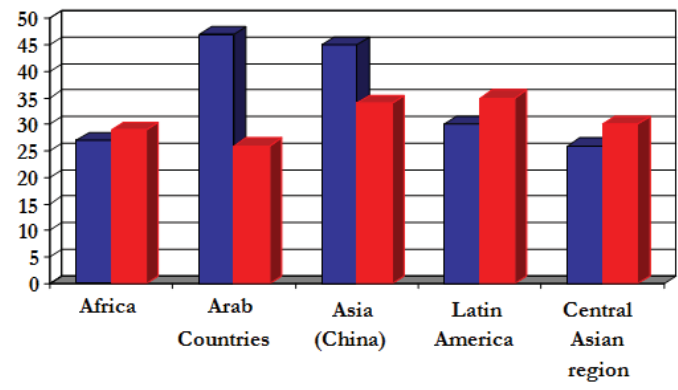

$\square$ Male Female

Figure 1. Quantitative composition of the sample by region of the world

\section{Results}

At the first stages of the study we have identified four tolerance types of the international students via cluster analysis. We conventionally named the selected group as "Real tolerant", "Tolerant in ethnic relations", "Tolerant in social communications", "Intolerant" students (tab. 1, fig. 2).

Fig. 1 shows that the "Real tolerant" students have higher indicators for all components of tolerance; the "Tolerant in ethnic relations" students have high levels of the ethnic and personality tolerance and the low level of social tolerance; the "Tolerant in social communications" students have a high level of social tolerance, an average level of personality tolerance and a low level of ethnic tolerance; the "Intolerant" students have the lowest indicators for all the components of tolerance. 
Table 1. Results of cluster analysis

\begin{tabular}{|c|c|c|c|c|}
\hline \multirow[b]{3}{*}{$\begin{array}{l}\text { Components of } \\
\text { tolerance }\end{array}$} & \multicolumn{4}{|c|}{ Types of tolerance } \\
\hline & \multirow[b]{2}{*}{$\begin{array}{c}\text { "Intolerant" } \\
(\mathrm{n}=42)\end{array}$} & \multicolumn{2}{|c|}{ "Selectively tolerant" } & \multirow[b]{2}{*}{$\begin{array}{c}\text { "Real tolerant" } \\
(n=82)\end{array}$} \\
\hline & & $\begin{array}{c}\text { "Tolerant in social } \\
\text { communications" }(n=119)\end{array}$ & $\begin{array}{l}\text { "Tolerant in ethnic relations" } \\
\qquad(\mathrm{n}=86)\end{array}$ & \\
\hline Ethnic tolerance & 2,73 & 3,29 & 4,31 & 4,79 \\
\hline $\begin{array}{l}\text { Personality } \\
\text { tolerance }\end{array}$ & 2,37 & 3,53 & 3,81 & 4,03 \\
\hline Social tolerance & 2,32 & 3,92 & 2,87 & 4,15 \\
\hline
\end{tabular}

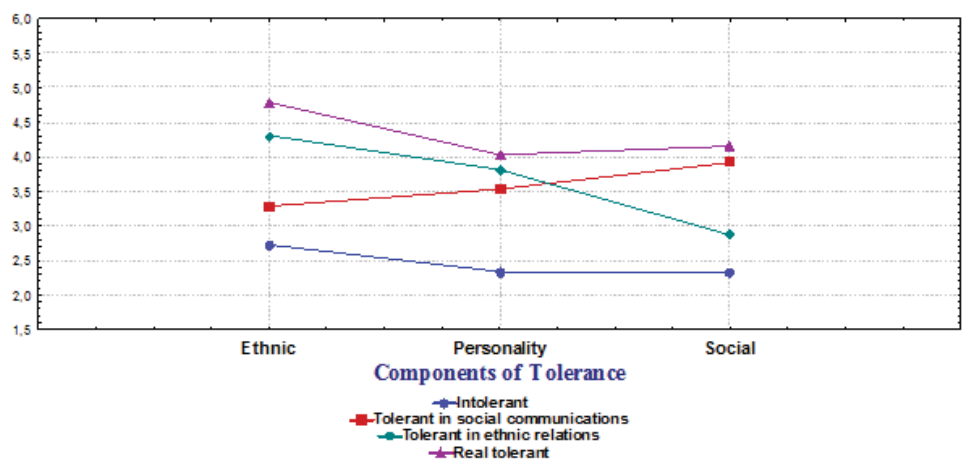

Figure 2. Types of Tolerance

Table 2 shows the distribution across clusters of students from different regions. It is interesting that the group of "Intolerant" students includes the highest number of the representatives of Latin America and China.

Table 2. Distribution across clusters of the students from different regions

\begin{tabular}{|c|c|c|c|c|c|c|}
\hline $\begin{array}{c}\text { Types of } \\
\text { tolerance }\end{array}$ & $\begin{array}{l}\text { Frequency } \\
\text { analysis }\end{array}$ & $\begin{array}{c}\text { Latin } \\
\text { America }\end{array}$ & China & $\begin{array}{c}\text { Central } \\
\text { Asia }\end{array}$ & $\begin{array}{c}\text { Arabian } \\
\text { countries }\end{array}$ & Africa \\
\hline \multirow{4}{*}{$\begin{array}{c}\text { Intolerant } \\
(n=42)\end{array}$} & Frequency & 15 & 16 & 4 & 3 & 4 \\
\hline & $\begin{array}{l}\text { Expected } \\
\text { frequency }\end{array}$ & 8,3 & 10,1 & 7,1 & 9,3 & 7,1 \\
\hline & $\%$ in 1 claster & $35,7 \%$ & $38,1 \%$ & $9,5 \%$ & $7,1 \%$ & $9,5 \%$ \\
\hline & $\%$ of the region & $23,1 \%$ & $20,3 \%$ & $7,1 \%$ & $4,1 \%$ & $7,1 \%$ \\
\hline \multirow{4}{*}{$\begin{array}{l}\text { Tolerant in } \\
\text { social } \\
\text { communi- } \\
\text { cations } \\
(\mathrm{n}=119)\end{array}$} & Frequency & 19 & 27 & 17 & 35 & 21 \\
\hline & $\begin{array}{c}\text { Expected } \\
\text { frequency }\end{array}$ & 23,5 & 28,6 & 20,3 & 26,4 & 20,3 \\
\hline & $\%$ in 2 claster & $16,0 \%$ & $22,7 \%$ & $14,3 \%$ & $29,4 \%$ & $17,6 \%$ \\
\hline & $\%$ of the region & $29,2 \%$ & $34,2 \%$ & $30,4 \%$ & $47,9 \%$ & $37,5 \%$ \\
\hline \multirow{4}{*}{$\begin{array}{l}\text { Tolerant in } \\
\text { ethnic relations } \\
(\mathrm{n}=86)\end{array}$} & Frequency & 18 & 25 & 14 & 17 & 12 \\
\hline & $\begin{array}{l}\text { Expected } \\
\text { frequency }\end{array}$ & 17,0 & 20,7 & 14,6 & 19,1 & 14,6 \\
\hline & $\%$ in 3 claster & $20,9 \%$ & $29,1 \%$ & $16,3 \%$ & $19,8 \%$ & $14,0 \%$ \\
\hline & $\%$ of the region & $27,7 \%$ & $31,6 \%$ & $25,0 \%$ & $23,3 \%$ & $21,4 \%$ \\
\hline \multirow{4}{*}{$\begin{array}{l}\text { Real tolerant } \\
\quad(n=82)\end{array}$} & Frequency & 13 & 11 & 21 & 18 & 19 \\
\hline & $\begin{array}{l}\text { Expected } \\
\text { frequency }\end{array}$ & 16,2 & 19,7 & 14,0 & 18,2 & 14,0 \\
\hline & $\%$ in 4 claster & $15,9 \%$ & $13,4 \%$ & $25,6 \%$ & $22,0 \%$ & $23,2 \%$ \\
\hline & $\%$ of the region & $20,0 \%$ & $13,9 \%$ & $37,5 \%$ & $24,7 \%$ & $33,9 \%$ \\
\hline
\end{tabular}


The representatives of the Arab countries dominated in the group of "Tolerant in social communications student". The small predominance of the representatives of China is in the group of the "Tolerant in ethnic relations" students. And the students from Central Asia relatively predominate in the group of the "Real tolerant" students.

At the second stage of the study we compared the types of tolerance with the features of intercultural adaptation of the international students from different regions (tab. 3).

Table 3 shows that the most significant difference is between the intercultural adaptation indicators of the real tolerant students and the students which are tolerant in social communication.

Table 3. Relations of the types of tolerance with the features of intercultural adaptation

\begin{tabular}{|c|c|c|c|c|}
\hline \multirow{2}{*}{$\begin{array}{c}\text { Intercultural } \\
\text { adaptation parameters }\end{array}$} & \multicolumn{4}{|c|}{ Types of tolerance } \\
\cline { 2 - 5 } & 1. "Intolerant" & $\begin{array}{c}\text { 2. "Tolerant in social } \\
\text { communications" }\end{array}$ & $\begin{array}{c}\text { 3. "Tolerant in } \\
\text { ethnic relations" }\end{array}$ & 4. "Real tolerant" \\
\hline Contentment & 4,62 & $4,30_{4}$ & 4,59 & $5,27_{2}$ \\
\hline Interactivity & $5,67_{2}$ & $4,30_{14}$ & 5,09 & $5,3_{2}$ \\
\hline Conformity & 5,29 & $4,48_{4}$ & 5,33 & $6,09_{2}$ \\
\hline Depression & $4,21_{4}$ & 3,37 & 3,33 & $2,94_{1}$ \\
\hline Nostalgia & 4,57 & $4,16_{34}$ & $4,97_{2}$ & $5,30_{2}$ \\
\hline Alienation & $3,95_{24}$ & $2,76_{1}$ & 3,09 & $2,49_{2}$ \\
\hline
\end{tabular}

Note: Subscripts are the numbers of the clusters between which there is a significant difference (Kruskal-Wallis test).

Table 3 also shows that the tolerant students have high rates of positive parameters of the intercultural adaptation and the lowest indicators of the depression and alienation. The students, who are tolerant in social communications, have low rates of positive adaptation parameters, but at the same time low indicators of the depression and alienation. The students, who are tolerant in the ethnic relations, have average indicators of the majority of intercultural adaptation parameters both positive and negative. An interesting fact is that the intolerant students have average or even high levels of positive adaptation parameters, but at the same time high levels of the depression and alienation.

\section{Discussion}

Thus, the results allowed us to give the general characteristics of students with different types of tolerance.

The smallest group of intolerant students includes 49 people (12.8\% of the sample). The students from Latin America and China dominated in this group. These students have the lowest rates of social, ethnic, and personality tolerance. They have ambivalent indicators of intercultural adaptation. On the one hand, they are satisfied with their adaptation to a foreign country, ready to interact with the new environment, and they do not feel a strong nostalgia for their homeland. On the other hand, their adaptation is difficult because of the strong feelings of doubt, anxiety, depression, emptiness, isolation, helplessness.

The group of students who are tolerant in social communication, is the largest, it includes 119 people $(36.2 \%$ of the sample).The students from the Arab countries relatively predominate in this group. The members of this group show more tolerance in social communication than in interethnic relations. They are not very satisfied with their adaptation to a foreign country, they do not seek to be included in the new environment, but they do not have a strong nostalgia, anxiety or helplessness.

The group of students who are tolerant in the ethnic relations includes 86 students ( $26.1 \%$ of the sample). The students from China relatively predominate in this group. They show more tolerance in interethnic relations than in social communication. They do not have many problems with adapting to a new culture.

The group, which we call "really tolerant" students, includes 82 persons ( $24.9 \%$ of the sample). They have both the highest rates of all the components of tolerance, and the most harmonious character of cross-cultural adaptation. The high rates of nostalgia of these students do not prevent their adaptation to the new culture.

\section{Conclusions}

Summing up the results of the study, it can be concluded that:

1. the four typical variants of tolerance in the international students have been exposed; 
2. the types of tolerance are related with features of intercultural adaptation of the international students

These data confirm the findings of the previous studies that tolerance is an important factor in the intercultural adaptation. The obtained data should be used in the trainings on intercultural communication and adaptation of the international students.

\section{Acknowledgement}

This research was kindly supported from the Russian Foundation for the Humanities, project № 11-06-00718-a ("Ethnic Tensions in Multi-Ethnic Educational Environment: Psychological and Pedagogical Aspects").

\section{References}

Chebotareva, E. Ju. (2011) Intercultural adaptation to Russia of students from Asia, Africa, Latin America and the Middle East. Bulletin of Peoples' Friendship University of Russia. Series: Psychology and Pedagogics, 3, 6-11.

Furnham, A., Heaven, P. (1999) Personality and social behaviour. Arnold, London.

Hannigan, T. P.(1990) Traits, attitudes, and skills that are related to intercultural effectiveness and their implications for cross-cultural training: A review of the literature. International Journal of Intercultural Relations, 14, 89-111.

Ibadova, T.I. (2011) The Problem of Tolerance in Modern Foreign Psychology. Bulletin of Peoples' Friendship University of Russia. Series: Psychology and Pedagogics, 3, 68-74.

Kovalenko, A.G., \& Chebotareva, E.Yu., \& Mikheeva, N.F., \& Larina, T.V., \& Novikova, I.A., \& Ebzeeva Yu.N., \& Maslova, O.V, \& Volk, M.I, \& Ibadova, T.I. (2009). Intercultural Communication: Linguistic and Psychological Aspects: Collective monograph. Moscow, Russia: Peoples' Friendship University of Russia (in Russian).

Lievens, F., \& Harris, M. M., \& Van Keer, E., \& Bisqueret, C. (2003) Predicting cross-cultural training performance: The validity of personality, cognitive ability, and dimensions measured by an assessment center and a behavior description interview. Journal of Applied Psychology. 2003, 88, 476-489.

Maslova, O.V. (2011)Basic Beliefs of Personality as Resource of Adaptation to New Culture. Bulletin of Peoples' Friendship University of Russia. Series: Psychology and Pedagogics, 3, $12-18$ (in Russian).

Mendenhall, M., \& Oddou, G. (1986) Acculturation profiles of expatriate managers: Implications for cross-cultural training programs. Columbia Journal of World Business, 21, 73-79.

Novikova, I.A. (2010) Relationship between the parameters of tolerance and cross-cultural adaptation of foreign students. Bulletin of Peoples' Friendship University of Russia. Series: Psychology and Pedagogics, 4, $24-28$ (in Russian).

Novikova, I.A. (2011) Tolerance as the factor of intercultural adaptation of foreign students of Peoples' Friendship University of Russia. Addendum to the International Psychology Bulletin (electronic edition). Retrieved <30.03.2012> at http://www.itopwebsite.com/morelP/Indigenous_Psychologies.html

Soldatova, G.U., Shaigerova L.A. (Eds) (2008) Psychodiagnostics of the personality tolerance. Moscow, Russia: Smysl (in Russian).

Stefanenko, T.G. (2009) Ethnic psychology (4th ed.) Moscow, Russia: Aspekt-Press (in Russian). 